\title{
Mitochondrial Abnormalities in Alzheimer's Disease
}

\author{
Keisuke Hirai,, ${ }^{1,4}$ Gjumrakch Aliev, ${ }^{2}$ Akihiko Nunomura, ${ }^{1,5}$ Hisashi Fujioka, ${ }^{1}$ Robert L. Russell, ${ }^{1}$ \\ Craig S. Atwood, ${ }^{1}$ Anne B. Johnson, ${ }^{6}$ Yvonne Kress, ${ }^{6}$ Harry V. Vinters, ${ }^{7}$ Massimo Tabaton, ${ }^{8}$ \\ Shun Shimohama, ${ }^{9}$ Adam D. Cash, ${ }^{1}$ Sandra L. Siedlak, ${ }^{1}$ Peggy L. R. Harris, ${ }^{1}$ Paul K. Jones, ${ }^{3}$ \\ Robert B. Petersen, ${ }^{1}$ George Perry, ${ }^{1}$ and Mark A. Smith ${ }^{1}$
}

\begin{abstract}
1/nstitute of Pathology, 2Department of Neurology, and ${ }^{3}$ Department of Epidemiology and Biostatistics, Case Western Reserve University, Cleveland, Ohio 44106, 4Pharmaceutical Research Laboratories I, Pharmaceutical Research Division, Takeda Chemical Industries Ltd., Osaka, 532-8686 Japan, 5Department of Psychiatry and Neurology, Asahikawa Medical College, Asahikawa, 078-8510 Japan, ${ }^{6}$ Department of Pathology, Albert Einstein College of Medicine, Bronx, New York 10461, ${ }^{7}$ Department of Pathology and Laboratory Medicine, University of California, Los Angeles, California 90024, ${ }^{8}$ Department of Neuroscience, University of Genova, 16132 Genova, Italy, and ${ }^{2}$ Department of Neurology, Kyoto University, Kyoto, 606-8507 Japan
\end{abstract}

The finding that oxidative damage, including that to nucleic acids, in Alzheimer's disease is primarily limited to the cytoplasm of susceptible neuronal populations suggests that mitochondrial abnormalities might be part of the spectrum of chronic oxidative stress of Alzheimer's disease. In this study, we used in situ hybridization to mitochondrial DNA (mtDNA), immunocytochemistry of cytochrome oxidase, and morphometry of electron micrographs of biopsy specimens to determine whether there are mitochondrial abnormalities in Alzheimer's disease and their relationship to oxidative damage marked by 8-hydroxyguanosine and nitrotyrosine. We found that the same neurons showing increased oxidative damage in Alzheimer's disease have a striking and significant increase in mtDNA and cytochrome oxidase. Surprisingly, much of the mtDNA and cytochrome oxidase is found in the neuronal cytoplasm and in the case of mtDNA, the vacuoles associated with lipofuscin. Morphometric analysis showed that mitochondria are significantly reduced in Alzheimer's disease. The relationship shown here between the site and extent of mitochondrial abnormalities and oxidative damage suggests an intimate and early association between these features in Alzheimer's disease.

Key words: Alzheimer's disease; free radicals; metabolism; mitochondria; neurodegeneration; oxidative stress
The pathological presentation of Alzheimer's disease (AD) involves selective pyramidal neuronal death and an accumulation of intraneuronal and extracellular fibrils, neurofibrillary tangles (NFT), and senile plaques, respectively (Katzman, 1986; Smith, 1998). In a series of studies, we and others have shown that oxidative stress is involved not only in damage to the proteins of NFT and senile plaques but also involves extensive damage to the cytoplasm of neuronal populations vulnerable to death during AD (Montine et al., 1996; Smith et al., 1996, 1997; Sayre et al., 1997). What is particularly striking regarding neuronal damage is that those neurons displaying oxidative damage show no overt signs of visible degeneration (Sayre et al., 1997; Smith et al., 1997), leading us to consider whether more subtle cytological abnormalities might be associated with oxidative damage.

We undertook this study to determine whether mitochondria could be involved in this process because they can be both targets of oxidative damage and sources of reactive oxygen. Dysf unction of mitochondrial electron transport proteins has been associated with the pathophysiology of AD (Blass and Gibson, 1991), as well as in Parkinson's disease (Parker et al., 1989). Those studies that

\footnotetext{
Received Oct. 13, 2000; revised Feb. 14, 2001; accepted Feb. 16, 2001.

This work was supported by National Institutes of Health Grants AG09287, AG14249, P50 AG16570, and NS38648, the American Health Assistance Foundation and the United Mitochondrial Diseaese Foundation.

K.H. and G.A. contributed equally to this study.

Correspondence should be addressed to Dr. Mark A. Smith, Institute of Pathology, Case Western Reserve University, 2085 Adelbert Road, Cleveland, OH 44106. E-mail: mas21@po.cwru.edu.

Copyright (C) 2001 Society for Neuroscience $\quad 0270-6474 / 01 / 213017-07 \$ 15.00 / 0$
}

analyzed mitochondrial function at the cellular level, through cytochrome oxidase activity measurements, have consistently shown activity deficits consistent with mitochondrial compromise (Wong-Riley et al., 1997). Furthermore, cytoplasmic hybrid cells in which mitochondria from sporadic cases of AD were fused with other cells also indicate a defect in mitochondria function in AD (Ghosh et al., 1999; Khan et al., 2000; Trimmer et al., 2000). However, these studies implicating mitochondrial abnormalities in $\mathrm{AD}$ were not focused on specific neuronal cytological abnormalities in mitochondria in vulnerable neurons and their relationship to oxidative damage.

In this study, we use cytological in situ hybridization, immunocytochemistry, and morphometry to determine whether mitochondrial abnormalities are associated with vulnerable neurons in AD. Our findings show major abnormalities in mitochondrial dynamics restricted to vulnerable neurons, suggesting an intimate relationship between mitochondria and oxidative damage in AD.

\section{MATERIALS AND METHODS}

\section{Tissue}

Brain tissue was obtained at autopsy from cases with a diagnosis of AD (Khachaturian, 1985; Mirra et al., 1991) as well as control cases with no clinical or pathological history of neurological disease. Hippocampal tissue, including the adjacent temporal cortex, cerebellum, and frontal cortex from 27 cases of AD (ages 57-93 years; postmortem intervals, 2-20.5 hr; average, $6.4 \mathrm{hr}$ ), 12 old control cases (ages 54-85 years; postmortem intervals, 3-34 hr; average, $13.8 \mathrm{hr}$ ), and eight young control cases (ages 3-49 years; postmortem intervals, 3-23 hr; average, $12.4 \mathrm{hr}$ ), was either fixed in methacarn (methanol-chloroform-acetic acid, 60:30: 
10) or $2 \%$ paraformaldehyde $-0.5 \%$ glutaraldehyde at $4^{\circ} \mathrm{C}$ for $16 \mathrm{hr}$ for light or electron microscopic examination, respectively. For light microscopy, after fixation, tissue was dehydrated through graded ethanol followed by xylene and embedded in paraffin. Sections, $6-\mu \mathrm{m}$-thick, were cut and mounted on silane (Sigma, St. Louis, MO)-coated standard glass microscope slides for in situ hybridization and immunocytochemistry. For electron microscopy, tissue was sectioned at $60 \mu \mathrm{m}$ using a Vibratome and immunodecorated with colloidal gold.
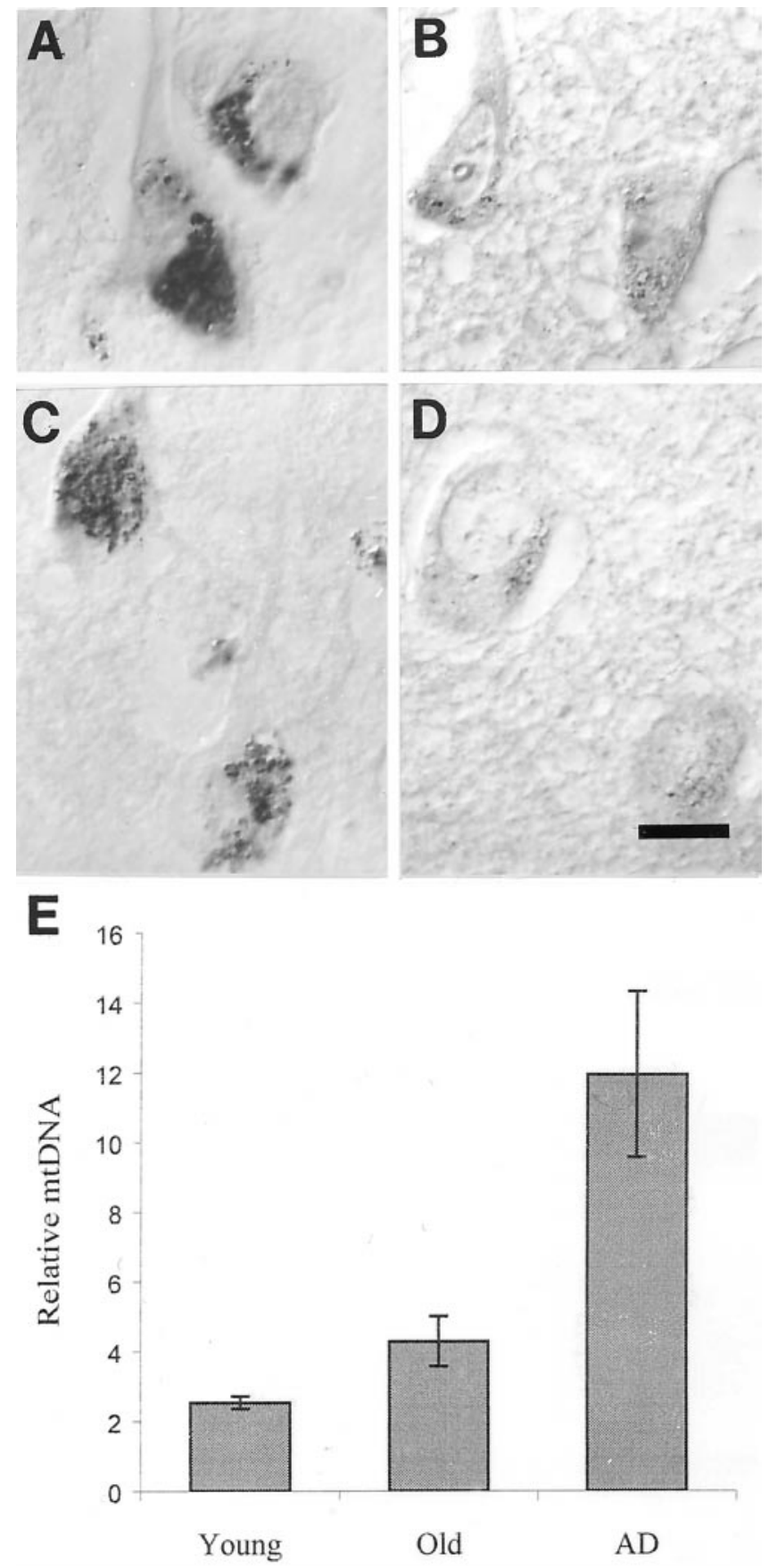

Figure 1. Pyramidal neurons of the hippocampus, cells highly vulnerable to death in $\mathrm{AD}$, show increased mtDNA in all cases of $\mathrm{AD}(A$, mtDNA $\Delta 5 \mathrm{~kb}$, chimeric probe; $C$, wild-type mtDNA) compared with controls $(B, \mathrm{mtDNA} \Delta 5 \mathrm{~kb}$, chimeric probe; $D$, wild-type mtDNA). $E$, Quantitative densitometric analysis of the level of mtDNA shows the increases are severalfold and significant ( $p=0.0034$; Student's $t$ test) for AD compared with old or young controls \pm SEMs. Scale bar, $10 \mu \mathrm{m}$.

\section{Biopsy}

Tissue was taken for diagnostic procedures from the frontal or temporal cortices of eight patients (age 53-84), most of which had been included in other clinicopathological studies (Stewart et al., 1992; Praprotnik et al., 1996a,b) and with a definite history (duration 3-11 years) and clinical presentation of dementia and fulfilling the National Institute of Neurological and Communicative Disorders and Stroke and the Alzheimer's Disease and Related Disorders Association working group criteria for probable AD (McKhann et al., 1984). Corresponding tissue from five patients (ages 62-80) suffering from various conditions such as hydrocephalus or brain tumor were also examined and used as controls. Tissue was fixed in $1.5 \%$ glutaraldehyde in cacodylate buffer and post-fixed in $1 \%$ osmium tetroxide for $1 \mathrm{hr}$ immediately after removal from the brain. After dehydration in graded ethanol and propylene oxide, the tissue was embedded in Epon 812, sectioned at silver interference color, electroncontrasted with uranyl acetate and lead citrate, and grids were viewed at $80 \mathrm{kV}$ using a JEOL 100CX electron microscope.

\section{In situ hybridization}

Light microscopy. In situ hybridization was performed according to the method of Nakamura et al. (1996) with some modifications. Probes used for in situ analysis of mitochondrial DNA (mtDNA) were wild-type and with the common $5 \mathrm{~kb}$ deletion (mtDNA $\Delta 5 \mathrm{~kb}$ ). Four oligonucleotide probes, three of $45 \mathrm{bp}$ and one of $29 \mathrm{bp}$ in length, were constructed for the present study. The probes, designated "chimera", include the mtDNA region from nucleotide coordinate 8454 to 8482 of ATPase subunit 8 and from 13460 to 13475 of NADH-coenzyme Q oxidoreductase subunit 5 and the "chimera short" included the mtDNA region from 8454 to 8482 . The probes designated as "wild 1" and "wild 2" contain a fragment that spans nucleotides from 10897 to 10941 and from 10981 to 11025 of ND4L. The GC content of each 45 bp probe is $51.1 \%$, and the sequences of the probes lack long palindromic sequences. All probes to mtDNA were synthesized, labeled by digoxigenin, and purified by Operon Technologies (Alameda, CA): AluI and 2 repeat sequences were found exclusively in nuclear DNA (Research Genetics, Huntsville, AL).

After deparaffinization, the sections were rinsed with $0.1 \mathrm{M}$ PBS, $\mathrm{pH}$ 7.4, for $10 \mathrm{~min}$. The sections were treated with $10 \mu \mathrm{g} / \mathrm{ml}$ proteinase $\mathrm{K}$ (Boehringer Mannheim, Indianapolis, IN) in $0.1 \mathrm{M}$ PBS for $20 \mathrm{~min}$ at $37^{\circ} \mathrm{C}$, rinsed in $0.1 \mathrm{M} \mathrm{PBS}$, then incubated in $0.2 \mathrm{M} \mathrm{HCl}$ for $10 \mathrm{~min}$ at room temperature (RT). After rinsing with $0.1 \mathrm{M}$ PBS, the sections were acetylated with $0.25 \%(\mathrm{v} / \mathrm{v})$ acetic anhydride in $0.1 \mathrm{M}$ triethanolamine for $10 \mathrm{~min}$ at RT. Next, the sections were treated with RNase A (Sigma) (50 $\mu \mathrm{g} / \mathrm{ml}$ ) at $37^{\circ} \mathrm{C}$ for $30 \mathrm{~min}$, rinsed in $0.1 \mathrm{M} \mathrm{PBS}$, and then dehydrated through a graded ethanol series up to $100 \%$ and allowed to air dry. Hybridization solution $[50 \%(\mathrm{v} / \mathrm{v})$ formamide, $2 \times \mathrm{SSC}, 10 \% \mathrm{w} / \mathrm{v}$ dextran

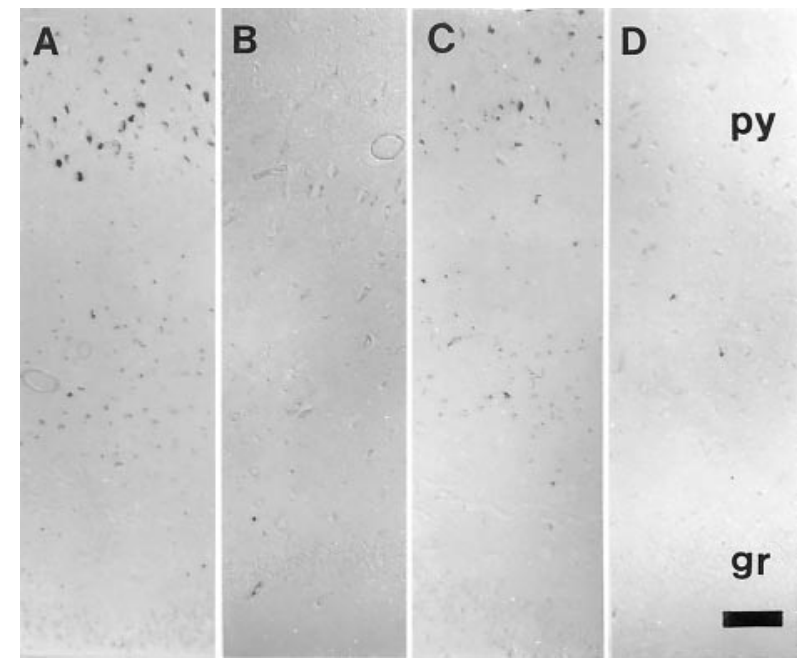

Figure 2. Both mtDNA $\Delta 5 \mathrm{~kb}$ (chimeric probe) $(A, B)$ or wild-type mtDNA (wild type 1) $(C, D)$ only show an increase in vulnerable neurons in $\mathrm{AD}$. In the hippocampus, we found that, whereas pyramidal neurons ( py) show mtDNA increase in $\mathrm{AD}(A, C)$ compared with controls $(B, D)$, other neuronal populations, e.g., granule cells of the dentate gyrus ( $g r)$, as well as glia, show no detectable signals. Scale bar, $100 \mu \mathrm{m}$. 


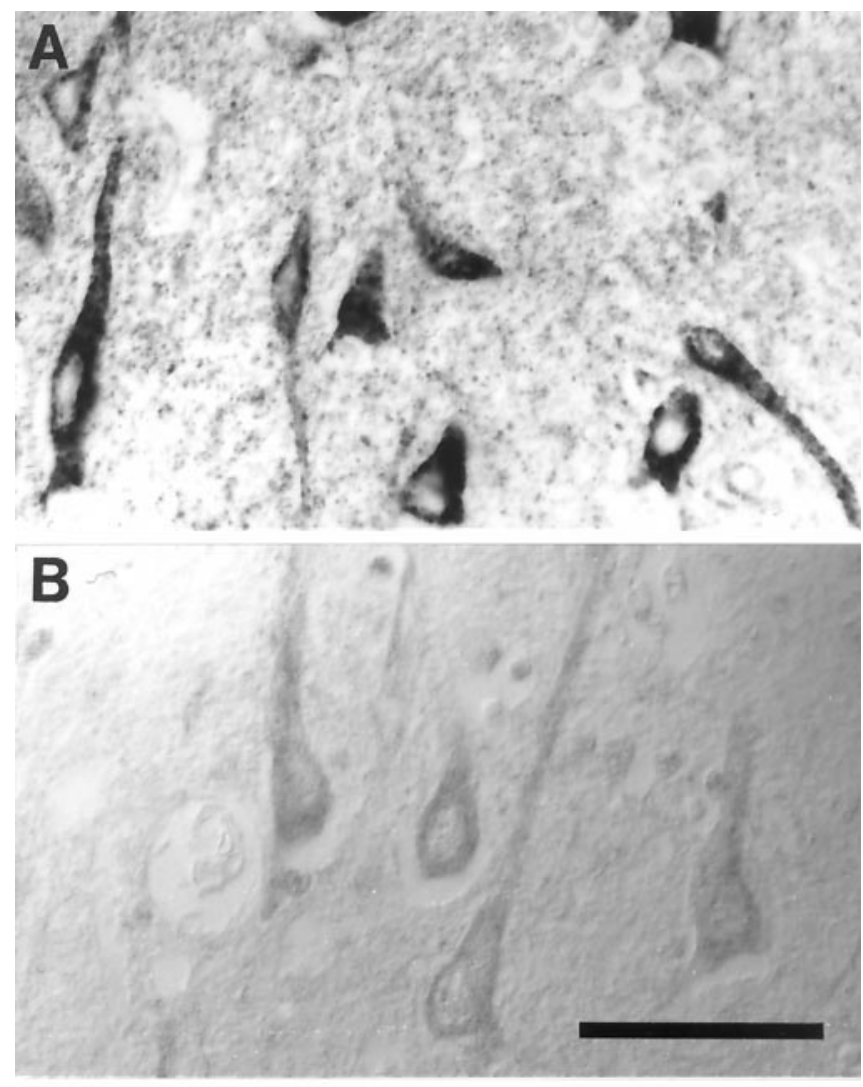

C

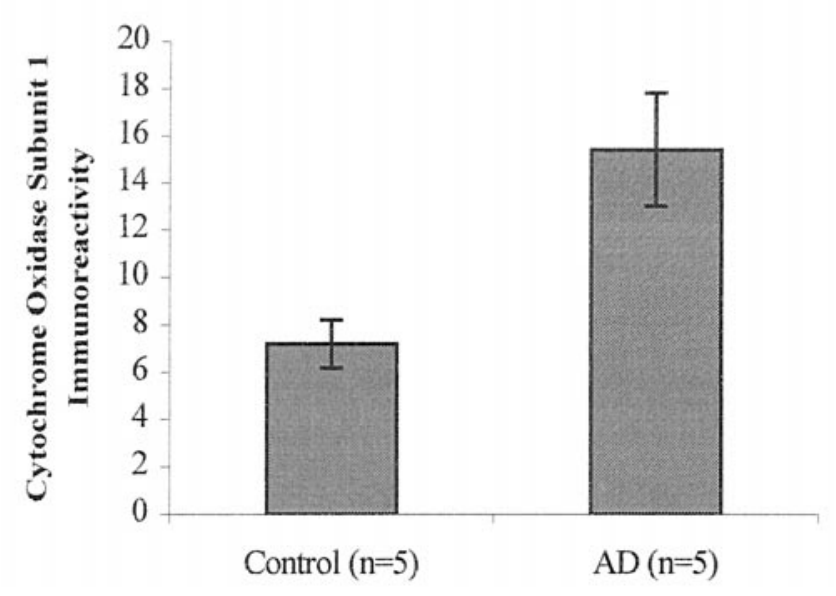

Figure 3. Cytochrome oxidase 1 immunoreactivity is increased severalfold in neurons in $\mathrm{AD}(A)$ compared with controls $(B)$ and as shown by quantitative densitometric analysis $(C)(p=0.013$; Student's $t$ test $) \pm$ SEM. Scale bar, $50 \mu \mathrm{m}$.

sulfate, $0.1 \mathrm{mg} / \mathrm{ml}$ sonicated salmon testis DNA (Sigma), $0.2 \mathrm{mg} / \mathrm{ml}$ yeast tRNA (Sigma), and $0.4-0.6 \mu \mathrm{g} / \mathrm{ml}$ digoxigenin-labeled probe] was boiled for $10 \mathrm{~min}$ at $100^{\circ} \mathrm{C}$. The sections were overlaid with $100 \mu \mathrm{l}$ of the hybridization solution, placed on a heating block for $5 \mathrm{~min}$ at $95^{\circ} \mathrm{C}$, and then hybridized overnight at $40^{\circ} \mathrm{C}$. After hybridization, the specimens were washed sequentially, once with $10 \mathrm{~mm}$ Tris-HCl, $\mathrm{pH} 7.4,500 \mathrm{~mm}$ $\mathrm{NaCl}, 1 \mathrm{~mm}$ EDTA, twice with $2 \times$ SSC $(1 \times$ SSC: $0.15 \mathrm{M} \mathrm{NaCl}, 15 \mathrm{~mm}$ sodium citrate, $\mathrm{pH} 7.4$ ), and once with $0.1 \times$ SSC. All washes were for 10 min at $37^{\circ} \mathrm{C}$. The sections were then washed twice with Tris-buffered saline (TBS; $50 \mathrm{~mm}$ Tris-HCl, $\mathrm{pH}$ 7.6, $150 \mathrm{~mm} \mathrm{NaCl}$ ) for $10 \mathrm{~min}$ at RT. After incubation in $10 \%$ normal goat serum (NGS) for $1 \mathrm{hr}$ at RT, slides were incubated with a monoclonal antibody to digoxigenin (1:250; Boehringer Mannheim) in $1 \%$ NGS overnight at $4^{\circ} \mathrm{C}$ and immunostained by the
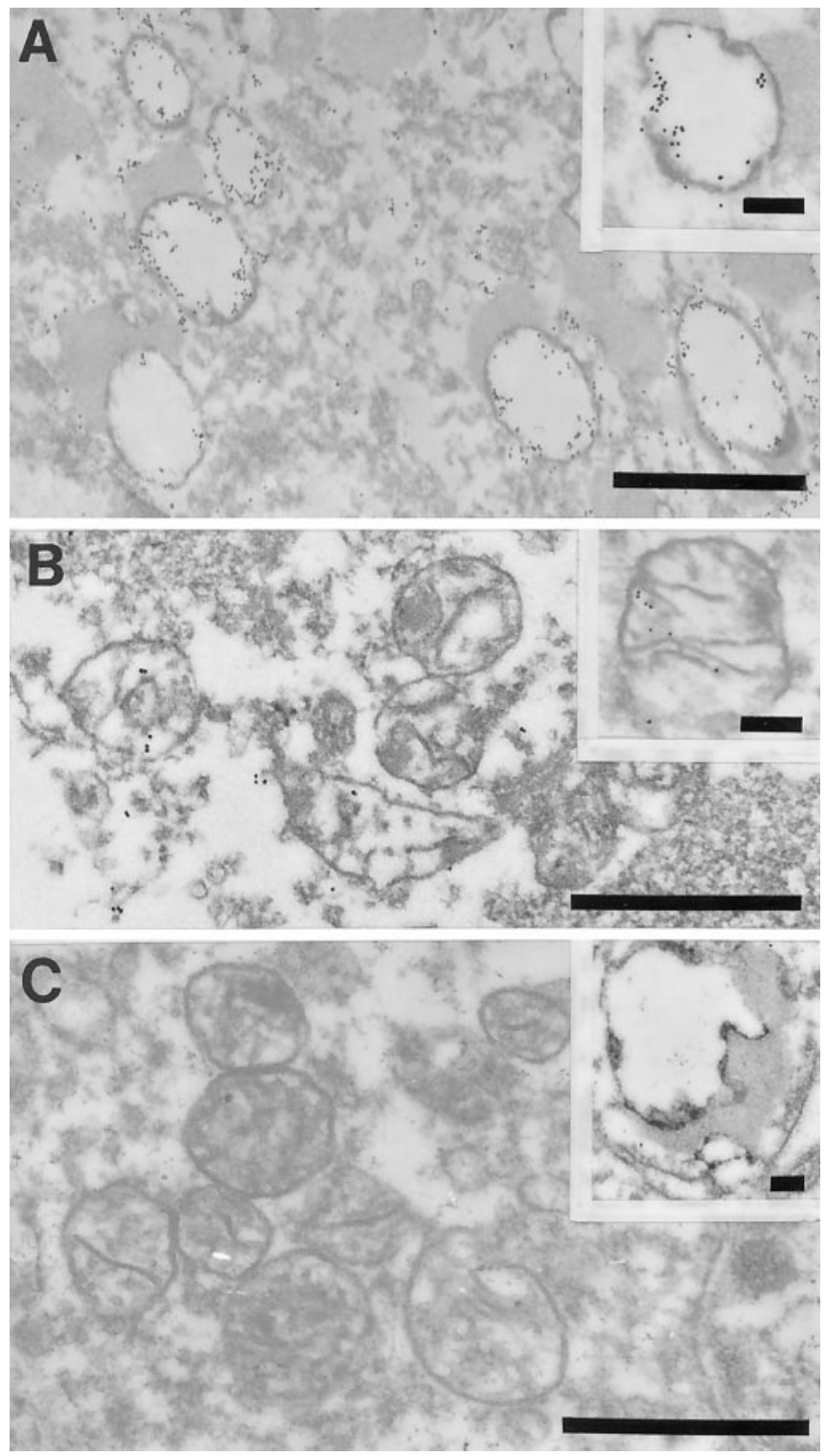

Figure 4. Ultrastructural examination of a pyramidal neuron in the hippocampus after in situ hybridization by using probes to wild mtDNA (wild type 1$)$ in $\mathrm{AD}(A, B)$ or mtDNA $\Delta 5 \mathrm{~kb}$ (chimeric probe) (insets, $A, B)$. The high density of gold particles was seen inside the vacuolar portions of lipof uscin granules, which likely represents autophagocytosis of damaged mitochondria in $\operatorname{AD}(A)$ and to a lesser extent in controls $(C$, inset $)$. In contrast, mitochondria with cristae in both $\mathrm{AD}(B)$ and control cases $(C)$ showed a lower level of mtDNA labeling $(C)$. Scale bars: $1 \mu \mathrm{m} ; 0.25 \mu \mathrm{m}$ (insets).

peroxidase-anti-peroxidase method (Sternberger, 1986), with 3,3' diaminobenzidine as cosubstrate. As controls, some specimens were processed as above but without the oligonucleotide probes and, in other cases, the hydrated sections were treated with a combination of $50 \mathrm{U} / \mathrm{ml}$ S1 nuclease (Boehringer Mannheim) and $50 \mathrm{U} / \mathrm{ml}$ DNase I (Boehringer Mannheim) overnight at $37^{\circ} \mathrm{C}$. In both cases, no positive signal was detected. Optical densities of in situ hybridization were measured for manually outlined neuronal cell bodies with a Quantimet 570C Image Processing and Analysis Systems (Leica, Nussloch, Germany) as previously described (Nunomura et al., 1999)

Electron microscopy. Vibratome sections were treated and hybridized to probes as described above. Next, they were washed twice with TBS (50 mM Tris- $\mathrm{HCl}, \mathrm{pH} 7.6,150 \mathrm{~mm} \mathrm{NaCl}$ ) for $10 \mathrm{~min}$ at RT, incubated in $10 \%$ NGS for $2 \mathrm{hr}$ at RT, and then incubated with a monoclonal antibody to digoxigenin (Boehringer Mannheim) diluted in 1\% NGS overnight at 
Figure 5. Examination of the morphology of mitochondria and lipofuscin in specimens removed at biopsy showed intact mitochondria $(A)$, mitochondria with broken cristae $(B)$, and vacuoles associates with lipofuscin indicated by a $V$ and lipofuscin indicated by an $L(C)$. Scale bars, $1 \mu \mathrm{m}$.
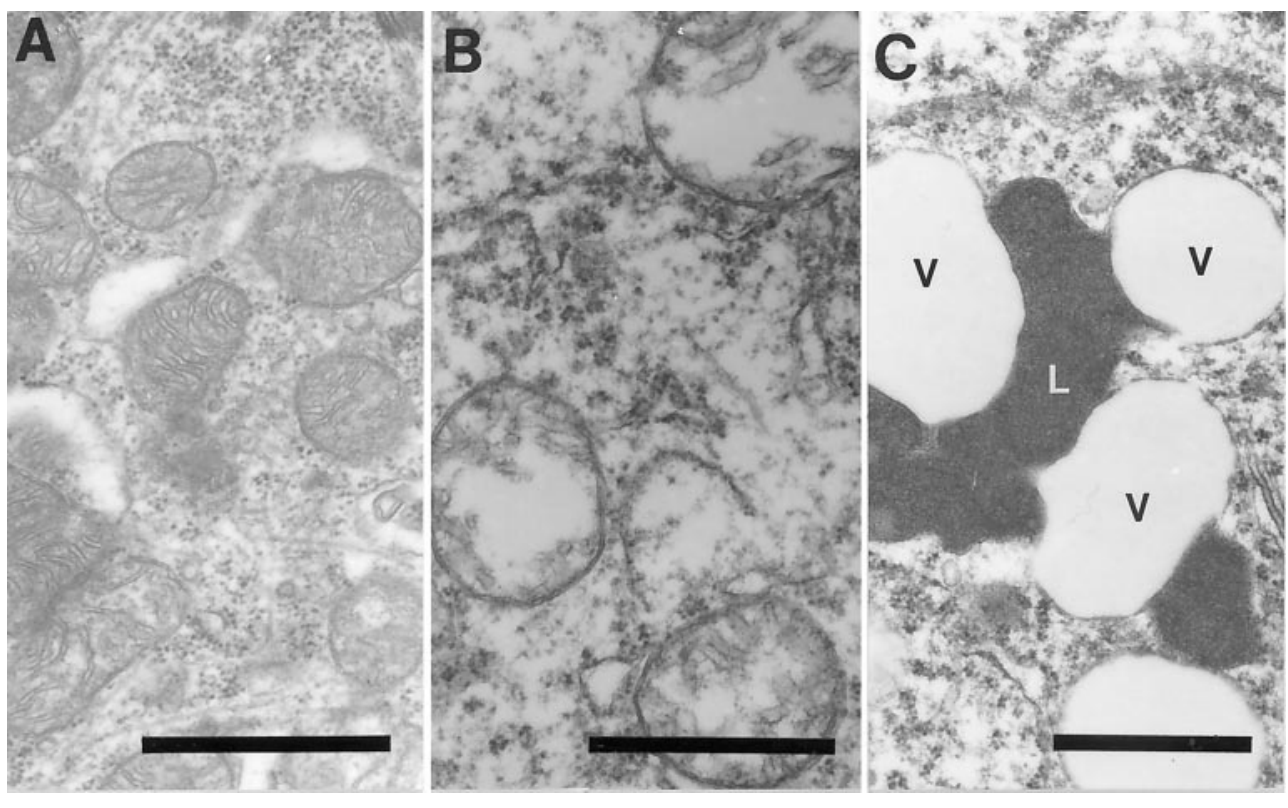

$4^{\circ} \mathrm{C}$. After rinses in $10 \% \mathrm{NGS}$, gold $(17 \mathrm{~nm})$-conjugated antibody to mouse IgG were applied for $4-24 \mathrm{hr}$ and thoroughly rinsed in PBS. Finally the sections are post-fixed in $2.5 \%$ glutaraldehyde for $1 \mathrm{hr}$ and again rinsed with PBS.

As controls, some specimens were processed as above but without the oligonucleotide probes, and in other cases the hydrated sections were treated with a combination of $50 \mathrm{U} / \mathrm{ml} \mathrm{S1}$ nuclease (Boehringer Mannheim) and $50 \mathrm{U} / \mathrm{ml}$ DNase I (Boehringer Mannheim) or with omission of the antibody to digoxigenin at $37^{\circ} \mathrm{C}$ for $1 \mathrm{hr}$. Finally, all sections were exposed to osmium tetraoxide for $1 \mathrm{hr}$ at RT, rinsed, dehydrated through acetone, and flat-embedded in Spurr's embedding media. Ultrathin sections were stained with uranylacetate and lead citrate and viewed in a JEOL 100CX electron microscope at $80 \mathrm{kV}$.

\section{Immunocytochemistry}

To identify the pathology of AD, we used antisera to $\tau$ (Perry et al., 1991) to show NFT and a monoclonal antibody (4G8) to A $\beta$ (Kim et al., 1988) for senile plaques. Nucleic acid and protein oxidative damage was respectively identified with antibodies to 8-hydroxyguanosine (8-OHG; Trevigen) and nitrotyrosine (clone 7A2; gift from J. S. Beckman, University of Alabama, Birmingham, AL). A monoclonal antibody to cytochrome oxidase-1 (clone 1D6; Molecular Probes, Eugene, OR) was also used in these studies. All immunostaining for light microscopy was by the peroxidase-anti-peroxidase method (Sternberger, 1986) and for electron microscopy by immunogold (Perry et al., 1985). Additionally, Congo red was used to identify the lesions of AD in some sections.

\section{Morphometry}

Micrographs were taken of neurons identified in the biopsy tissue at the plane containing the nucleolus at magnification of $5000 \times$ and additionally at $20,000 \times$ so that a montage including the entire cytoplasm could be made. Between 2 and 10 neurons were examined for each case. Photomicrographs were examined with a Zeiss stereomicroscope at $10-20 \times$ and the following organelles were identified and counted for each neuron: intact mitochondria, mitochondria with broken cristae, vacuoles associated with lipofuscin, and lipofuscin. Total mitochondria was the sum of intact mitochondria and mitochondria with broken cristae. Each structure was outlined and the area was determined (NIH Image J program) and compared to the total cytoplasmic area excluding the nucleus.

Differences between groups were compared by the Student's $t$ test as well as two-way ANOVA ( $F$ test).

\section{RESULTS}

In situ analysis for mtDNA using oligonucleotide probes revealed a consistent and significant increase in mtDNA levels in cases of $\mathrm{AD}$ (Fig. $1 A, C, E$ ) compared with age-matched (Fig. $1 B, D, E)$ or young controls (Fig. $1 E$ ) for all the probes used $(p=0.0034$;
Student's $t$ test) with no significant difference between probes. Increases in both mtDNA $\Delta 5 \mathrm{~kb}$ (Fig. $2 A, B$ ) or wild-type mtDNA (Fig. 2C,D) was restricted to neurons, particularly those large vulnerable neurons of the hippocampus and neocortex. Neuronal labeling was seen in granular structures in the perinuclear cytoplasm and not noted in axons or dendrites. The sites labeled in the cytoplasm were DNase- but not RNase-sensitive (data not shown), whereas hybridization to nuclear sequences (AluI and 2) were restricted to the nucleus (data not shown). Importantly, in the hippocampus, we found that although pyramidal neurons (py) show mtDNA increase in AD (Fig. $2 A, C$ ) compared with controls (Fig. $2 B, D$ ), other neuronal populations, e.g., granule cells of the dentate gyrus (gr) as well as glia, show no increase. Importantly, a similar neuronal specificity was demonstrated in the frontal and temporal cortex, whereas in the cerebellum, a region only mildly affected by $\mathrm{AD}$, there was no disease-related increase in mtDNA, wild-type or deleted, in any cellular populations (data not shown). The restriction of increased mtDNA to vulnerable neurons means that although the increase is striking in vulnerable neurons (Fig. 1), when examined in a regional context (Fig. 2), the change is small explaining the inability of previous biochemical analysis of tissue representing a variety of cell types to detect the substantial increase in mtDNA shown here. In our own comparison of mtDNA in AD and control cases by PCR, we did not find a significant and consistent increase in mtDNA (K. Hirai, M. A. Smith, and G. Perry, unpublished observations). No statistically significant correlation was found between our findings and postmortem interval or agonal status by regression analysis.

The increase in mitochondrial components was not restricted to mtDNA because the mitochondrial protein cytochrome oxidase was also significantly elevated in the same neurons (Fig. 3) ( $p=0.013$; Student's $t$ test). To examine whether the increased mtDNA and mitochondrial protein noted in AD marked increased mitochondria or more mtDNA and cytochrome oxidase 1 per mitochondria, we examined the site of the increase by ultrastructure. We found only a weak in situ hybridization or immunoreactivity signal from mitochondria in AD (Fig. 4C) as well as control samples, not unexpected based on the expectation of 2-10 mtDNA for each individual mitochondria. However, we also 
A

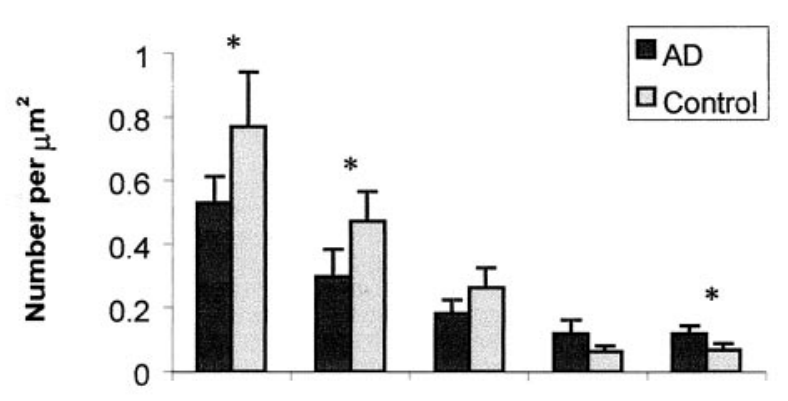

B

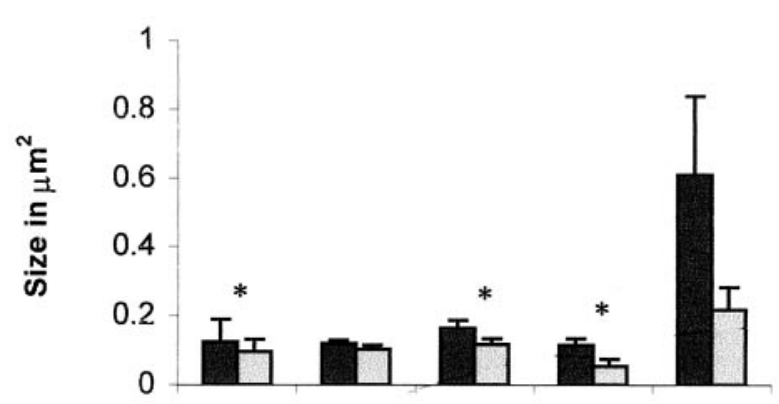

C

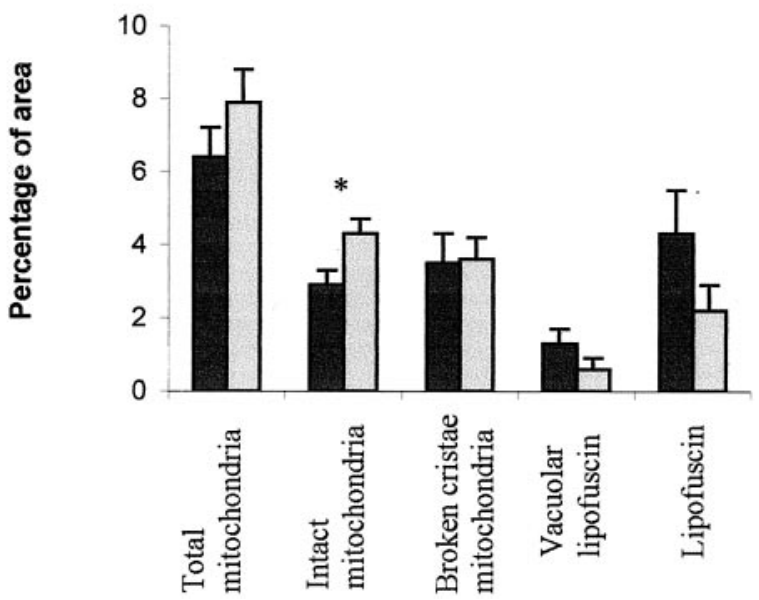

Figure 6. Morphometric analysis of the number $(A)$, size $(B)$, and percentage coverage $(C)$ of cytoplasmic area by intact mitochondria, mitochondria with broken cristae, total mitochondria (intact plus mitochondria with broken cristae), vacuoles associated with lipofuscin, and lipof uscin in cases of AD and controls. Whereas percentage coverage of intact mitochondria decreases in $\mathrm{AD}(p=0.012)$, no significant changes were noted in vacuoles associated with lipofuscin $(p=0.056)$, mitochondria with broken cristae $(p>0.10)$, or lipof uscin $(p>0.08)$. Although the size of lipofuscin did not change in $\operatorname{AD}(p=0.095)$, that of the vacuoles associated with lipofuscin significantly increased $(p=0.029)$. Statistical comparison by the $F$ test. ${ }^{*}$ indicates significant difference between $\mathrm{AD}$ and control cases.

found mtDNA and cytochrome oxidase-1 (data not shown) in the cytosol and in the case of mtDNA, also in vacuoles associated with lipofuscin (Fig. 4A,B). Confirming the light microscopic analysis, no mitochondria in axons or dendrites showed marked mtDNA proliferation (data not shown), and no signal was detected after the omission of either oligonucleotide probe, antibody to digoxigenin, or with previous treatment with DNases (data not shown). These findings indicate that the increase in

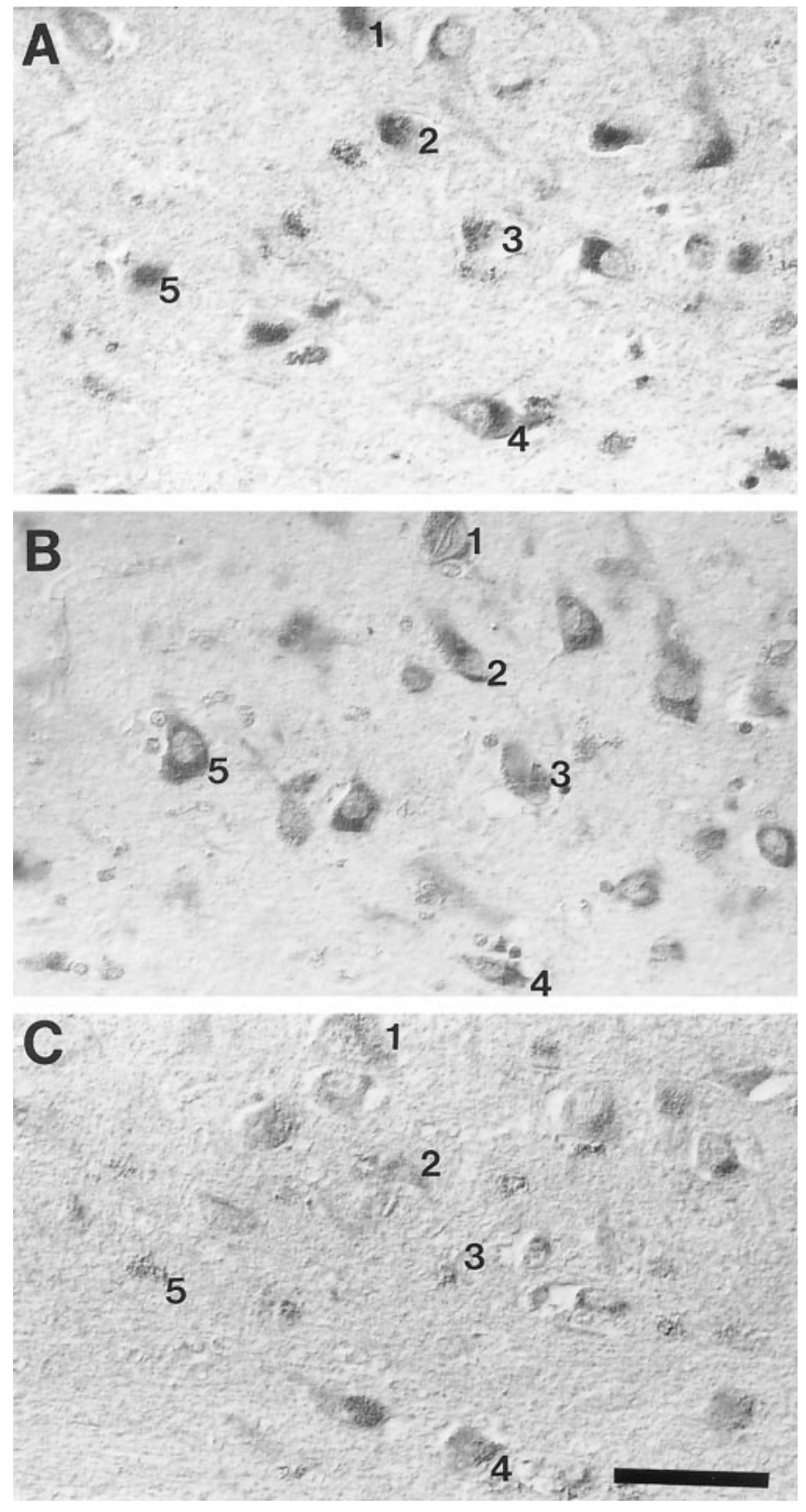

Figure 7. The distribution of neurons showing increased mtDNA $\Delta 5 \mathrm{~kb}$ (chimeric probe) $(A), 8-\mathrm{OHG}(B)$, and nitrotyrosine $(C)$ immunoreactivity in AD completely overlaps. Number indicates the same neurons in adjacent serial sections. Scale bar, $50 \mu \mathrm{m}$.

mitochondrial markers in AD is related to their accumulation in the cytoplasm and the late autophagosomes of lipofuscin.

To evaluate the change in mitochondria in AD independent of DNA or protein-related probes as well as whether these changes could be noted in living patients before agonal state and soon after the onset of dementia, we quantitatively examined mitochondria and lipofuscin in specimens removed at biopsy (Fig. 5). Morphometric analysis (Fig. 6) showed that the area of intact mitochondria is significantly decreased in $\mathrm{AD}(p=0.012 ; F$ test $)$ whereas there is no difference between the area of damaged mitochondria in AD or control cases. Because mitochondria are highly susceptible to morphological artifacts such as broken cristae, through inadequate fixation, that controls and AD cases showed similar frequency of mitochondria with broken cristae 
suggests that fixation was similar for each group. Whereas the percentage of area for vacuoles associated with lipofuscin and lipofuscin were both increased in $\mathrm{AD}$, the difference was not significant. As reported earlier (Dowson et al., 1998), we noted that the size of lipofuscin granules and vacuoles is larger in AD, but only the latter reached significance ( $p=0.029 ; F$ test). Although only six of the neurons in the AD cases contained neurofibrillary tangles, we found no significant differences in mitochondria or lipofuscin in those neurons compared with others.

Oxidative damage marked by $8-\mathrm{OHG}$ and nitrotyrosine was increased in the same neurons displaying mtDNA proliferation (Fig. 7). Also, as we previously noted for 8-OHG (Nunomura et al., 1999) and nitrotyrosine (Smith et al., 1997), one of the most striking features of the mitochondrial abnormalities is its relatively uniform effect on entire populations of vulnerable neurons. Therefore, these data support an intimate topographic and probably temporal relationship between neuronal oxidative damage and mitochondrial abnormalities.

\section{DISCUSSION}

In this study, we addressed whether there are mitochondrial abnormalities in vulnerable neurons by examining mtDNA, mitochondrial protein, and mitochondrial number in AD. We found both increased mtDNA and protein in AD. Ultrastructural examination showed the increased mtDNA and protein was found in the cytoplasm and in the vacuoles associated with lipofuscin, a lysosome that, in previous studies of cells, has been suggested as the site of mitochondrial degradation by autophagy (Brunk et al., 1992). Morphometry of the organelles of samples obtained at biopsy demonstrates there is, in fact, a significant decrease in mitochondria of vulnerable neurons in AD. These findings indicate vulnerable neurons in $\mathrm{AD}$ have increased mitochondrial degradation products, suggesting either greater turnover of mitochondria by autophagy or a reduction of proteolytic turnover leading to accumulation of mtDNA and mitochondrial protein. These mitochondrial components are likely damaged, because hydroxynonenal adducts to lipoic acid (Humphries and Szweda, 1998), the prosthetic group of two key Krebs cycle enzymes, can be found in the same vacuoles substantiates the view that these components are nonfunctional (G. Perry, M. A. Smith, and L. Szweda, unpublished observations). Also, because cytochrome oxidase must be membrane-bound to function, our findings are consistent with the low functional activity of many mitochondrial enzymes in AD (Wong-Riley et al., 1997).

The restriction of damaged mtDNA to neurons vulnerable to death in AD means that although the increase is striking on a per cell basis, when seen in the context of brain tissue, the change is very selective. The selectivity likely explains the conflicting results of previous biochemical analyses of mtDNA by PCR analysis. When we analyzed mtDNA changes by PCR, we also found only small differences between samples from AD and controls even in cases shown by in situ hybridization to show a fourfold increase (data not presented). This restriction to vulnerable neurons is the same found for oxidative damage, suggesting that an intimate relationship exists between them. The absence of mtDNA accumulation in non-neuronal cells does not mean that they do not also show changes in mitochondria. In a previous morphometric study, significant reduction in mitochondria density was found in endothelial cells (Stewart et al., 1992). Blass et al. (1990) and Blass and Gibson (1991) have also elegantly shown mitochondrial abnormalities in fibroblasts and other cells ob- tained from patients with AD. The striking changes noted here may reflect as much how different categories of neurons deal with mitochondrial abnormalities, and such an interpretation is consistent with the findings of recent work with cytoplasmic hybrids that show mitochondria derived from non-neuronal cells from cases of AD have substantial energetic deficiencies (Ghosh et al., 1999; Khan et al., 2000; Trimmer et al., 2000). It is tempting to consider that the range of oxidative balance abnormalities noted in $\mathrm{AD}$ stem from a fundamental mitochondrial deficiency, but clearly more work is necessary to establish such a relationship. Although differences in mtDNA heredity may be important to our observations, the restriction of changes to vulnerable neurons only in cases of $\mathrm{AD}$, rather than a more generalized change involving all cell types, indicates mitochondrial inheritance alone is not the only factor, but probably differences in mitochondrial turnover and metabolism as well as oxidant defense between different categories of cells are involved and require further clarification in future studies (Ito et al., 1999). Among the possible mechanisms underlying cellular specificity, reactive oxygen in vulnerable neurons may damage mitochondria while reducing their degradation (Friguet et al., 1994). Alternatively, mitochondria are likely not being transported to the axon properly consistent with the reduced number of microtubules seen in neurons in AD (A. D. Cash, M. A. Smith and G. Perry, unpublished observations).

That abnormalities occur in neurons lacking neurofibrillary tangles places mitochondria abnormalities as the earliest cytopathological change in AD. Other changes of AD could very well be linked to mitochondria because blockage of mitochondrial energy production shifts amyloid $\beta$-protein precursor metabolism to the production of more amyloidgenic forms of amyloid- $\beta$ (Gabuzda et al., 1994), induces the production of A68 antigen (Blass et al., 1990), and activates the mitogen-activated protein kinase pathway (Luo et al., 1997; Perry et al., 1999; Zhu et al., 2000, 2001), all features of $\mathrm{AD}$.

\section{REFERENCES}

Blass JP, Gibson GE (1991) The role of oxidative abnormalities in the pathophysiology of Alzheimer's disease. Rev Neurol (Paris) 147:513-525.

Blass JP, Baker AC, Ko L, Black RS (1990) Induction of Alzheimer antigens by an uncoupler of oxidative phosphorylation. Arch Neurol 47:864-869.

Brunk UT, Jones CB, Sohal RS (1992) A novel hypothesis of lipof uscinogenesis and cellular aging based on interactions between oxidative stress and autophagocytosis. Mutat Res 275:395-403.

Dowson JH, Mountjoy CQ, Cairns MR, Wilton-Cox H, Bondareff W (1998) Lipopigment changes in Purkinje cells in Alzheimer's disease. J Alzheimer's Dis 1:71-79.

Friguet B, Stadtman ER, Szweda LI (1994) Modification of glucose-6phosphate dehydrogenase by 4-hydroxy-2-nonenal. Formation of crosslinked protein that inhibits the multicatalytic protease. J Biol Chem 269:21639-21643.

Gabuzda D, Busciglio J, Chen L, Matsudaira P, Yankner BA (1994) Inhibition of energy metabolism alters the processing of amyloid precursor protein and induces a potentially amyloidogenic derivative. J Biol Chem 269:13623-13628.

Ghosh SS, Swerdlow RH, Miller SW, Sheeman B, Parker WD Jr, Davis RE (1999) Use of cytoplasmic hybrid cell lines for elucidating the role of mitochondrial dysfunction in Alzheimer's disease and Parkinson's disease. Ann NY Ácad Sci 893:176-191.

Humphries KM, Szweda LI (1998) Selective inactivation of alphaketoglutarate dehydrogenase and pyruvate dehydrogenase: reaction of lipoic acid with 4-hydroxy-2-nonenal. Biochemistry 37:15835-15841.

Ito S, Ohta S, Nishimaki K, Kagawa Y, Soma R, Kuno S-Y, Komatsuzaki Y, Mizusawa H, Hayashi J-I (1999) Functional integrity of mitochondrial genomes in human platelets and autopsied brain tissues from elderly patients with Alzheimer's disease. Proc Natl Acad Sci USA 96:2099-2103.

Katzman R (1986) Alzheimer's disease. N Engl J Med 314:964-973. 
Khachaturian ZS (1985) Diagnosis of Alzheimer's disease. Arch Neurol 42:1097-1105.

Khan SM, Cassarino DS, Abramova NN, Keeney PM, Borland MK, Trimmer PA, Krebs CT, Bennett JC, Parks JK, Swerdlow RH, Parker Jr WD, Bennett Jr JP (2000) Alzheimer's disease cybrids replicate beta-amyloid abnormalities through cell death pathways. Ann Neurol 48:148-155.

Kim KS, Miller DL, Sapienza VJ, Chen CMJ, Bai C, Grundke-Iqbal I, Currie JR, Wisniewski HM (1988) Production and characterization of monoclonal antibodies reactive to synthetic cerebrovascular amyloid peptide. Neurosci Res Commun 2:121-130.

Luo Y, Bond JD, Ingram VM (1997) Compromised mitochondrial function leads to increased cytosolic calcium and to activation of MAP kinases. Proc Natl Acad Sci USA 94:9705-9710.

McKhann GD, Drachman DA, Folstein MF, Katzman R, Price D, Stadlan EM (1984) Clinical diagnosis of Alzheimer's disease: report of the NINCDS-ADRDA work group under the auspices of Department of Health and Human Services task force on Alzheimer's disease. Neurology 34:939-944.

Mirra SS, Heyman A, McKeel D, Sumi SM, Crain BJ, Brownlee LM, Vogel FS, Hughes JP, van Belle G, Berg L (1991) The consortium to establish a registry for Alzheimer's disease (CERAD). Part II. Standardization of the neuropathologic assessment of Alzheimer's disease. Neurology 41:479-486.

Montine TJ, Amarnath V, Martin ME, Strittmatter WJ, Graham DG (1996) E-4-hydroxy-2-nonenal is cytotoxic and cross-links cytoskeletal proteins in P19 neuroglial cultures. Am J Pathol 148:89-93.

Nakamura N, Hattori N, Tanaka M, Mizuno Y (1996) Specific detection of deleted mitochondrial DNA by in situ hybridization using a chimera probe. Biochim Biophys Acta 1308:215-221.

Nunomura A, Perry G, Pappolla MA, Wade R, Hirai K, Chiba S, Smith MA (1999) RNA oxidation is a prominent feature of vulnerable neurons in Alzheimer's disease. J Neurosci 19:1959-1964.

Parker WD, Boyson SJ, Parks JK (1989) Abnormalities of the electron transport chain in idiopathic Parkinson's disease. Ann Neurol 26:719723.

Perry G, Rizzuto N, Autilio-Gambetti L, Gambetti P (1985) Paired helical filaments from Alzheimer disease patients contain cytoskeletal components. Proc Natl Acad Sci USA 82:3916-3920.

Perry G, Kawai M, Tabaton M, Onorato M, Mulvihill P, Richey P, Morandi A, Connolly JA, Gambetti P (1991) Neuropil threads of Alzheimer's disease show a marked alteration of the normal cytoskeleton. J Neurosci 11:1748-1755.

Perry G, Roder H, Nunomura A, Takeda A, Friedlich AL, Zhu X, Raina
AK, Holbrook N, Siedlak SL, Harris PLR, Smith MA (1999) Activation of neuronal extracellular receptor kinase (ERK) in Alzheimer disease links oxidative stress to abnormal phosphorylation. NeuroReport 10:2411-2415.

Praprotnik D, Smith MA, Richey PL, Vinters HV, Perry G (1996a) Plasma membrane fragility in dystrophic neurites in senile plaques of Alzheimer's disease: an index of oxidative stress. Acta Neuropathol 91:1-5.

Praprotnik D, Smith MA, Richey PL, Vinters HV, Perry G (1996b) Filament heterogeneity within the dystrophic neurites of senile plaques suggests blockage of fast axonal transport in Alzheimer's disease. Acta Neuropathol 91:226-235.

Sayre LM, Zelasko DA, Harris PLR, Perry G, Salomon RG, Smith MA (1997) 4-Hydroxynonenal-derived advanced lipid peroxidation end products are increased in Alzheimer's disease. J Neurochem 68:2092-2097.

Smith MA (1998) Alzheimer disease. In: International review of neurobiology (Bradley JY, Harris RA, eds), pp 1-54. San Diego: Academic.

Smith MA, Perry G, Richey PL, Sayre LM, Anderson VM, Beal MF, Kowall N (1996) Oxidative damage in Alzheimer's. Nature 382:120-121.

Smith MA, Harris PLR, Sayre LM, Beckman JS, Perry G (1997) Widespread peroxynitrite-mediated damage in Alzheimer's disease. J Neurosci 17:2653-2657.

Sternberger LA (1986) Immunocytochemistry, Ed 3. New York: Wiley.

Stewart PA, Hayakawa K, Akers M-A, Vinters HV (1992) A morphometric study of the blood-brain barrier in Alzheimer's disease. Lab Invest 67:734-742.

Trimmer PA, Swerdlow RH, Parks JK, Keeney P, Bennett Jr JP, Miller SW, Davis RE, Parker Jr WD (2000) Abnormal mitochondrial morphology in sporadic Parkinson's and Alzheimer's disease cybrid cell lines. Exp Neurol 162:37-50.

Wong-Riley M, Antuono P, Ho K-V, Egan R, Hevner R, Liebl W, Huang Z, Rachel R, Jones J (1997) Cytochrome oxidase in Alzheimer's disease: biochemical, histochemical, and immunohistochemical analyses of the visual and other systems. Vision Res 37:3593-3608.

Zhu X, Rottkamp CA, Boux H, Takeda A, Perry G, Smith MA (2000) Activation of p38 pathway links tau phosphorylation, oxidative stress and cell cycle related events in Alzheimer disease. J Neuropathol Exp Neurol 59:880-888.

Zhu X, Raina AK, Rottkamp CA, Aliev G, Perry G, Boux H, Smith MA (2001) Activation and redistribution of c-Jun N-terminal kinase/stress activated protein kinase in degenerating neurons in Alzheimer's disease. J Neurochem 76:435-441. 